\title{
Promovendo a saúde escolar: a experiência de Hong Kong na parceria saúde e educação
}

Sonia Maria Pereira Vidigal*

Lee A, Tsang C, Lee SH, et al A comprehensive "Healthy Schools Programme" to promote school health: the Hong Kong experience in joining the efforts of health and education sectors

Journal of Epidemiology \& Community Health 2003;57:174-177.

O texto A comprehensive "Healthy Schools Programme to promote school health: the Hong Kong experience in joining the efforts of health and education sectors", de 2003, foi escrito por autores de diferentes departamentos e instituições, sendo três acadêmicos da Chinese University of Hong Kong — Departamento de Medicina da Comunidade e da Família, departamento escola de Saúde Pública e departamento de Educação - e o quarto autor, um membro do programa de saúde pública da cidade de Hong Kong.

Esta composição já demonstra algo defendido pelos autores, que investir na Educação como forma de desenvolver hábitos saudáveis é algo que depende de parcerias de vários setores, as áreas da Saúde, da Educação e dos Serviços Sociais, de forma a serem trabalhadas as diferentes perspectivas envolvidas no tema.

Por meio deste curto artigo, os autores defendem que a reflexão e ampliação da ideia de saúde é um dos fatores que contribuem para a educação, na perspectiva de que a sociedade moderna

* Pedagoga, Mestre e Doutora em Educação pela Universidade de São Paulo (FE-USP). 
demanda que as pessoas tenham mais do que habilidades para o trabalho e para o cotidiano, mas que a educação explore, também, valores e atitudes. A defesa desta ampla abrangência da educação é rica e bastante atual, mas no texto eles se limitam a discutir que esta ampliação da perspectiva da Educação implica incluir decisões relacionadas à saúde.

É certo que, como os autores também afirmam, a Educação para a Saúde pode ser um excelente recurso de prover informações e de ajudar as pessoas a mudarem suas atitudes e seu comportamento, proporcionando que desenvolvam estilos de vida mais saudáveis.

Nesse sentido, as escolas devem ser consideradas como espaço para promover a saúde. Não na mesma linha da crítica de Gramsci (2000), que aponta a escola como choque de tensões e combinações entre intencionalidades e demandas distintas, mas como espaço de formação para a conscientização de aspectos que são inerentes à saúde e não considerados na perspectiva tradicional.

Os autores citam ainda a implantação de um programa em Hong Kong. Por meio dele foram observados dificultadores, como a falta de recursos e de oportunidade de treinamento, o que não é uma dificuldade restrita desses autores nem desta área.

Também não parece novidade o destaque dado de que mais do que se estabelecer um currículo, devemos apostar no treinamento de professores de forma a promover conhecimento a respeito das áreas envolvidas. Porém, os autores destacam qual a ideia que este treinamento quer transformar: a abordagem tradicional de se fixar apenas os aspectos físicos da questão da saúde e na ideia de que ela sempre está atrelada a mensagens negativas.

A nova abordagem defendida inclui desenvolver a autoestima e as habilidades sociais, propiciando que os professores devam saber tratar a comunidade mais ampla e pensar sobre ela.

Assim como outros assuntos que se referem a valores, este artigo também defende que o tema seja trabalhado de maneira transversal, e que as atividades promovidas formem um currículo informal, variando de acordo com a necessidade de cada escola. 
A Chinese University of Hong Kong, em colaboração com as maiores escolas locais, estabeleceu parcerias que incluem, entre outras ações, cursos de treinamento, publicação de periódicos da comunidade escolar, pesquisa a respeito da saúde escolar, seminários e conferências.

Apesar de o estudo não ter conseguido perceber se houve mudança de atitude, considerou que houve, sim, mudança na maneira de pensar dos participantes da pesquisa, ampliando para uma visão mais holística e abrangente, que leva em consideração os aspectos psicológicos e sociais do bem-estar.

Este é um ponto que esbarra neste e em vários outros estudos, o quanto a transformação de concepção se relaciona também com a transformação nas atitudes.

Um estudo escrito com tantas mãos poderia ter aprofundado mais vários aspectos, entre eles, a concepção atual de saúde que se quer desenvolver por meio da educação, que nos foi apresentada mais pela negação do que não se queria defender. Ao terminar a leitura deste artigo, fica uma sensação de que cada aspecto apresentado seria melhor entendido com mais pormenores. Talvez o grande benefício seja a divulgação de que este trabalho está sendo feito, para que os interessados no tema possam buscar outros artigos dos mesmos autores.

\section{Referências}

GRAMSCI, A. Cadernos do cárcere. Volume 3. Maquiavel. Notas sobre o Estado e a política. Rio de Janeiro: Civilização Brasileira, 2000. 